\title{
Enhanced Resolution in the Capillary Electrophoretic Separation of Double-Stranded DNA Using Dextran Sulfate and Its Application to the Analysis of PCR Products
}

\author{
Hidetoshi Arakawa, Kunio Uetanaka, Akio Tsuji and Masako Maeda \\ School of Pharmaceutical Sciences, Showa University, Hatanodai, Shinagawa, Tokyo 142, Japan
}

Keywords Capillary electrophoresis, DNA, dextran sulfate, PCR products, carboxymethyl cellulose

At present, PCR is utilized in the diagnosis of infectious and hereditary diseases by amplifying a very small amount of DNA by about 100000 times. ${ }^{1}$ The DNA fragments generated by PCR are mainly between 100 and 1000 base pairs long. Recently, an analysis of PCR products is carried out by capillary electrophoresis (CE) based on the separation of doublestranded DNA (ds DNA), because this method enables an easy analysis of ds DNA fragments that are 100 to 1000 bp in length. This method can be automated and offers rapid results, high resolution and high reproducibility compared to conventional electrophoresis. Recently, the use of entangled polymer solutions ${ }^{2}$ has become the preferred method for the analysis of ds DNA fragments by CE. The principle of separation using a polymer solution is similar to that using a gel. When the concentration of the polymer solution is increased, the polymer chains become entangled, forming a transient network of obstacles. This serves as a sieving matrix that provides separation. This method offers several advantages to gels. For example, the polymerization of gel in the capillary is unnecessary; further, the same capillary can be used repeatedly because the polymer solution can be replaced after every analysis, and thus reproducible separation can be obtained in every application. A cellulose derivative (methylcellulose ${ }^{3,4}$, hydroxyethylcellulose ${ }^{2}$, hydroxypropylcellulose $^{5,6}$ ), poly(vinyl alchol) ${ }^{7}$, glucomannan ${ }^{8}$ and linear polyacrylamide ${ }^{9}$ as entangled polymer are used for separating the ds DNA. We have reported on a system for separating ds DNA fragments using carboxymethyl cellulose (CMC) as a polymer solution and dextran sulfate as an enhancement reagent, as well as its applications to gene diagnosis using PCR. ${ }^{10}$ However, the migration time was gradually increased dependent on an increase in the number of separations due to a decrease in the velocity of electroosmosis (EOF), even when the inside wall of the capillary was washed with a sodium hydroxide solution after each analysis. The day-to-day reproducibility of the migration time decreased as a result, and the capillary needed to be renewed after 10 to 20 analyses. In this study, we developed a reproducible separation system for DNA and PCR products. This method utilizes CMC and dextran sulfate as a polymer solution and uses a capillary coated with acrylamide to eliminate EOF.

\section{Apparatus}

A Model 270A capillary electrophoresis system (ABI, Foster City, CA, USA) was used. The separations were monitored on-column at $260 \mathrm{~nm}$.

\section{Materials and methods}

Carboxymethyl cellulose sodium. $\quad\left(\left(\mathrm{C}_{6} \mathrm{H}_{7} \mathrm{O}_{2}(\mathrm{OH})_{x}\right.\right.$ $\left.\left.\left(\mathrm{OCH}_{2} \mathrm{COONa}\right)_{y}\right)_{n}, x+y=3, n \div 500\right)(\mathrm{CMC})$ was purchased from Tokyo Kasei (Tokyo, Japan). $\phi \times 174$ RFDNA-Hae III digested (DNA MW Marker 4) was obtained from Nippon Gene (Osaka, Japan). The 100 base-pair ladder was from Pharmacia. Dextran sulfate (MW 8000) and $\gamma$-methacryloxypropyltrimethoxysilane were purchased from Sigma (St Louis, USA). Acrylamide-HG, $N, N, N^{\prime}, N^{\prime}$-tetramethylethylenediamine (TEMED) and ammonium persulfate (APS) were from Wako (Osaka, Japan). Silica capillary tubing $(0.05 \mathrm{~mm}$ i.d. $\times 0.375 \mathrm{~mm}$ o.d.) was obtained from GL Sciences

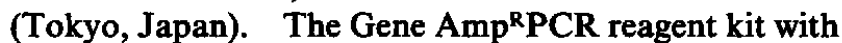
Amplitaq ${ }^{R}$ DNA polymerase was from Perking-Elemer Cetus (Norwalk, USA). Fused-silica capillary tubing ( $70 \mathrm{~cm}$ (48 $\mathrm{cm}$ to the detector)) was used. The inside wall of the tube was coated with a covalently attached layer of acrylamide according to the methods of Paulus et al. ${ }^{11}$ A coating solution consisting of $3 \%$ acrylamide and $2 \mu \mathrm{l}$ of TEMED solution and $50 \mu \mathrm{l}$ of $10 \%(\mathrm{w} / \mathrm{v})$ APS solution was quickly introduced into the capillary treated with $50 \%(\mathrm{v} / \mathrm{v}) \gamma$-methacryloxypropyltrimethoxysilane by using a vacuum-injection system equipped with an ABI Model $270 \mathrm{~A}$ for $10 \mathrm{~min}$ and left stand for at least $2 \mathrm{~h}$. The running buffer was $25 \mathrm{mM}$ Tris-glycine buffer (pH 8.4) containing $0.5 \%$ carboxymethyl cellulose-Na $(n=500), 5 \%$ dextran sulfate-Na salt (MW: 8000$)$ and 
$5 \mathrm{mM}$ EDTA. This buffer was injected into the capillary by pressure. The sample was injected into the capillary by pressure (typically $2 \mathrm{~s}, 0.5 \mathrm{psi}$ ). This injection was performed automatically by incorporating a second injection step in the method. Electrophoresis was performed at $10 \mathrm{kV}$ and $30^{\circ} \mathrm{C}$. For the $\mathrm{CE}$ experiment, the electrode of the injection side was attached to the negative site of a power supply. The separations were monitored on-column at $260 \mathrm{~nm}$.

\section{Results and Discussion}

PCR is widely used as a diagnostic tool. A specific DNA fragment can be amplified exponentially by PCR using 4 kinds of bases (dATP, dGTP, dCTP, dTTP), DNA polymerase, and two primers (about 20 oligomers). The ds DNA fragment (PCR product) amplified by PCR, unreacted reagents and dimers of the primers are contained in the reaction mixture after amplificaton. The separation of PCR products by CE using an entangled polymer solution has been described by Schwart $^{5}$ and Ulfelder et al. $^{6}$ However, the separation was not complete, because an ultrafiltration step was required to desalt the sample and to remove superfluous PCR reaction products. We previously developed a $\mathrm{CE}$ separation method for DNA using CMC as a polymer, and dextran sulfate as an enhancer of resolution, with non-coated capillary tubing. The separation system elutes DNA fragments by EOF with no interference in the separation of ds DNA fragments. However, the migration time was increased by decreasing EOF; the day-to-day reproducibility was low as a result.

In the present study, we developed a system for separating DNA having high reproducibility for the migration time, using a polymer solution of $\mathrm{CMC}$ and dextran sulfate and by coating the capillary so as to eliminate EOF. The optimal concentrations of CMC and dextran sulfate were examined for the separation of ds DNA of between 100 and $1000 \mathrm{bp}$. In our previous study, the optimum CMC concentration for the separation of DNA fragments of between 72 and 1353 bp was experimentally determined to be $0.5 \%$. This concentration was adopted for the present experiment. Since a CMC polymer solution without dextran sulfate is unable to separate ds DNA fragments $(100-1000 \mathrm{bp})$, the effect of dextran sulfate on the separation of DNA was also studied.

At present, dextran sulfate of three molecular weights is commercially available $\left(5 \times 10^{3}, 8 \times 10^{3}\right.$ and $\left.5 \times 10^{4}\right)$ : $8 \times 10^{3} \mathrm{MW}$ dextran sulfate provided a better separation of DNA fragments of $<200 \mathrm{bp}$ than $5 \times 10^{3} \mathrm{MW}$ and $5 \times 10^{4} \mathrm{MW}$ (data not shown), and was used as an adjunct of the CMC polymer solution used in the experiments. The optimal concentration of this dextran sulfate was studied under the conditions of capillary tubing of $42 \mathrm{~cm}$ $\left(20 \mathrm{~cm}\right.$ to the detector) and voltage of $6 \mathrm{kV}$ and $30^{\circ} \mathrm{C}$. Figure 1 shows the effect of the dextran sulfate $\left(8 \times 10^{3}\right.$ MW) concentration on the separation of $\phi \times 174$ RF-

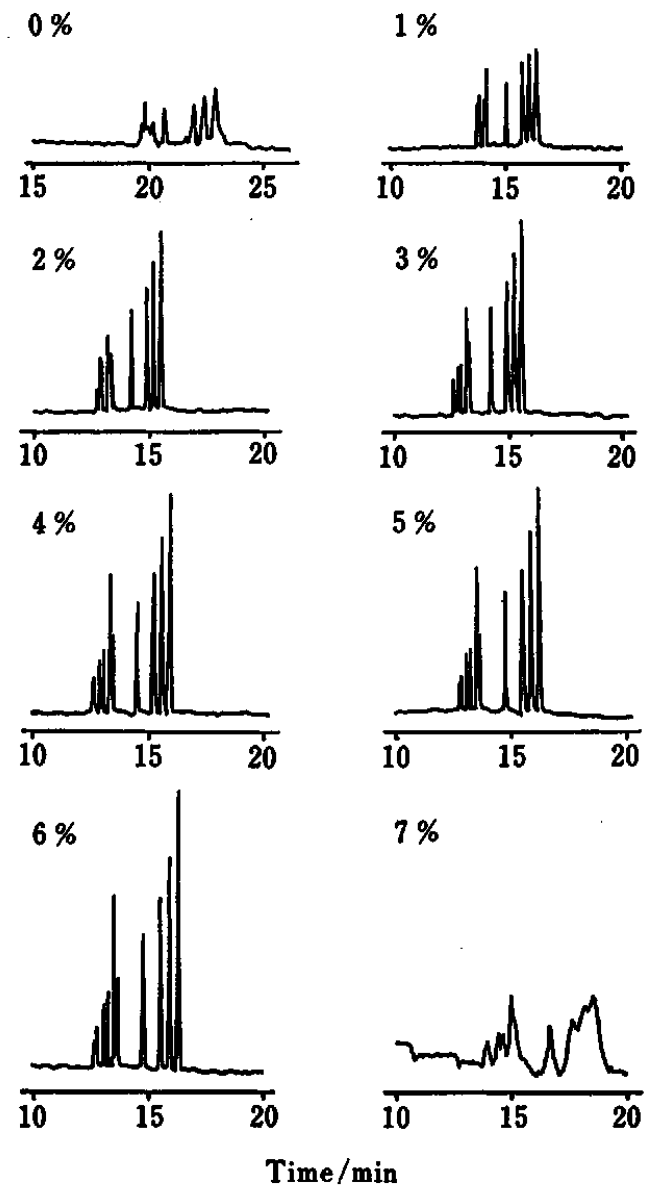

Fig. 1 Effect of the dextran sulfate concentration on the separation of fragments of Hae III digested $\phi \times 174$ RFDNA in a polymer solution of $0.5 \%$ carboxymethyl cellulose. (The separation was performed with a capillary length of $42 \mathrm{~cm}$ at $6 \mathrm{kV}$ and $30^{\circ} \mathrm{C}$ ).

DNA fragments digested with Hae III in a $0.5 \%$ CMC polymer solution. As shown in Fig. 1, the optimum separation was obtained at $5 \%$ of dextran sulfate. Why the addition of dextran sulfate to the sieving buffer improves the resolution of DNA fragments is not clear. However, an increase in the UV absorbance (about 5 fold for $872 \mathrm{bp}$ ) and a decrease in the migration time of DNA fragments were observed upon the addition. Therefore, dextran sulfate probably changes the structure and charge of DNA during electrophoresis, similar to the effect of an intercalation dye reported by Schwartz et al. ${ }^{6}$ Further, the optimal conditions of the capillary length and voltage were determined as described in method. The separation of a 100-base ladder of a DNA marker obtained under these optimal conditions is shown in Fig. 2. The elution order was determined from a fragment of low molecular weight. The efficiency of this separation method was evaluated by the separation of a 100-base ladder of a DNA marker. The result showed a large theoretical plate number of $4 \times 10^{5}$ for $100 \mathrm{bp}$. The precision of this method was studied by within assay and the day-to-day separation of fragments of Hae III 


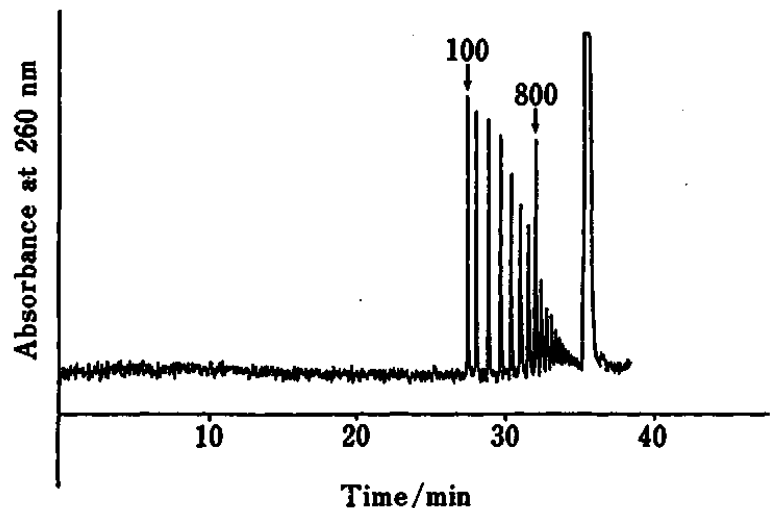

Fig. 2 Separation of 100 base pair ladder in a polymer solution of $0.5 \%$ carboxymethyl cellulose and $5 \%$ dextran sulfate (The separation was performed with a capillary length of $70 \mathrm{~cm}$ at $10 \mathrm{kV}$ and $30^{\circ} \mathrm{C}$ ).

digested $\phi \times 174$ RFDNA. The reproducibility of within assay and day-to-day were $0.54-0.58 \%(n=5)$ and $1.25-$ $1.28 \%(n=9)$, respectively.

Thus, this separation system produces highly reproducible results compared to those methods that use non-coated capillary tubing ${ }^{11}$, and is a useful tool for DNA analysis.

\section{Application to the analysis of PCR products}

The separation of PCR products was carried out by the proposed method; $500 \mathrm{bp}$ fragments were amplified by PCR of $\lambda$ phage DNA, and the PCR products were separated directly by CE. The separation of PCR products is shown in Fig. 3. With this method, the PCR reagent does not influence the separation of PCR products. A rapid analysis is required for diagnostic and clinical applications. However the running time of this method for the analysis of PCR products was about $50 \mathrm{~min}$. This can be decreased by onehalf by excluding PCR junk by replacing the polymer solution after the separation of the DNA fragments of interest. As described above, this system is accurate and gives high resolution, enabling the direct analysis of PCR. Full automation of PCR is feasible with this CE system.

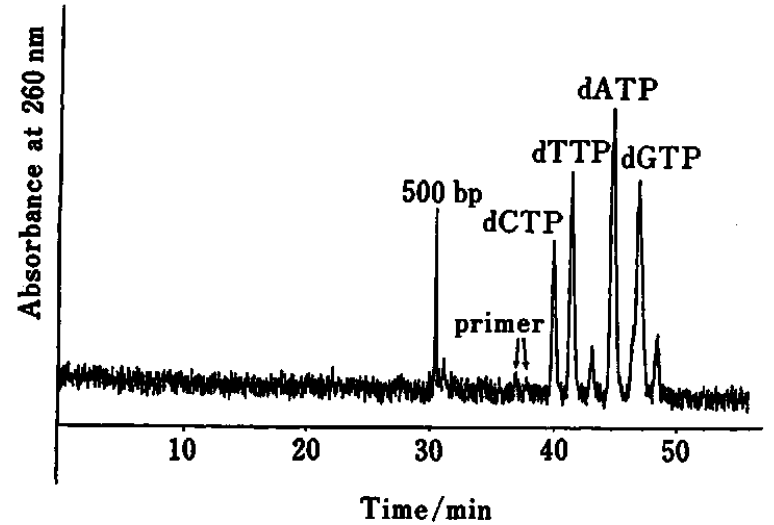

Fig. 3 Separation of PCR product ( $\lambda$ phage $500 \mathrm{bp}$ ) in a polymer solution of $0.5 \%$ carboxymethyl cellulose and $5 \%$ dextran sulfate (The separation was performed with a capillary length of $70 \mathrm{~cm}$ at $10 \mathrm{kV}$ and $30^{\circ} \mathrm{C}$ ).

\section{References}

1. R. K. Saiki, S. Scharf, F. Faloona, K. B. Mullis, G. T. Horn, H. A. Erlich and N. Arnheim, Science [Washington, D.C.], 230, 1350 (1985).

2. P. D. Grossman and D. S. Soane, J. Chromatogr., 559, 257 (1991).

3. M. Strege and A. Lagu, Anal. Chem., 63, 1233 (1991).

4. Y. Baba, N. Ishimaru, K. Samata and M. Tsuhako, $J$. Chromatogr. A, 653, 329 (1993).

5. H. E. Schwart, K. Ulfelder, F. J. Sunzeri, M. P. Busch and R. G. Brownlee, J. Chromatogr., 559, 267 (1991).

6. K. J. Ulfelder, H. E. Schwartz, J. M. Hall and F. J. Sunzeri, Anal. Biochem., 200, 260 (1992).

7. M. H. Kleemiss, M. Gilges and G. Schomburg, Electrophoresis, 14, 515 (1993).

8. T. Izumi, M. Yamaguchi, K. Yoneda, T. Isobe, T. Okuyama and T. Shinoda, J. Chromatogr. A, 652, 41 (1993).

9. Y. F. Pariat, J. Berka, D. N. Heiger, T. Schmitt, M. Vilenchik, A. S. Cohen, F. Foret and B. L. Karger, $J$. Chromatogr. A, 652, 57 (1993).

10. H. Arakawa, A. Tsuji and M. Maeda, Brnseki Kagaku, 46, 101 (1997).

11. A. Paulus and J. I. Ohms, J. Chromatogr., 507, 113 (1990). 